\title{
Web-based online resources about adverse interactions or side effects associated with complementary and alternative medicine: a systematic review, summarization and quality assessment
}

\author{
Jeremy Y. $\mathrm{Ng}^{*}{ }^{\mathbb{D}}$, Vanessa Munford and Harmy Thakar
}

\begin{abstract}
Background: Given an increased global prevalence of complementary and alternative medicine (CAM) use, healthcare providers commonly seek CAM-related health information online. Numerous online resources containing CAM-specific information exist, many of which are readily available/accessible, containing information shareable with their patients. To the authors' knowledge, no study has summarized nor assessed the quality of content contained within these online resources for at least a decade, specifically pertaining to information about adverse effects or interactions.
\end{abstract}

Methods: This study provides summaries of web-based online resources that provide safety information on potential interactions or adverse effects of CAM. Specifically, clinicians are the intended users of these online resources containing patient information which they can then disseminate to their patients. All online resources were assessed for content quality using the validated rating tool, DISCERN.

Results: Of 21 articles identified in our previously published scoping review, 23 online resources were eligible. DISCERN assessments suggests that online resources containing CAM-specific information vary in quality. Summed DISCERN scores had a mean of $56.13(S D=10.25)$ out of 75 . Online resources with the highest total DISCERN scores across all questions included Micromedex (68.50), Merck Manual (67.50) and Drugs.com (66.50). Online resources with the lowest total scores included Drug Information (33.00), Caremark Drug Interactions (42.50) and HIV Drug Interactions (43.00). The DISCERN questions that received the highest mean score across all online resources referred to whether the risks were described for each treatment (4.66), whether the aims were clear (4.58), whether the source achieved those aims (4.58), and whether the website referred to areas of uncertainty (4.58). The DISCERN questions that received the lowest mean score across all online resources assessed whether there was discussion about no treatment being used (1.29) and how treatment choices would affect quality of life (2.00).

Conclusion: This study provides a comprehensive list of online resources containing CAM-specific information. Informed by the appraisal of these resources, this study provides a summarized list of high quality, evidence-based,

*Correspondence: ngjy2@mcmaster.ca

Department of Health Research Methods, Evidence, and Impact, Faculty

of Health Sciences, McMaster University, Michael G. DeGroote Centre for

Learning and Discovery, Room 2112, 1280 Main Street West, Hamilton,

ON L8S 4K1, Canada

(c) The Author(s) 2020. Open Access This article is licensed under a Creative Commons Attribution 4.0 International License, which permits use, sharing, adaptation, distribution and reproduction in any medium or format, as long as you give appropriate credit to the original author(s) and the source, provide a link to the Creative Commons licence, and indicate if changes were made. The images or other third party material in this article are included in the article's Creative Commons licence, unless indicated otherwise in a credit line to the material. If material is not included in the article's Creative Commons licence and your intended use is not permitted by statutory regulation or exceeds the permitted use, you will need to obtain permission directly from the copyright holder. To view a copy of this licence, visit http://creativecommons.org/licenses/by/4.0/. The Creative Commons Public Domain Dedication waiver (http://creativeco mmons.org/publicdomain/zero/1.0/) applies to the data made available in this article, unless otherwise stated in a credit line to the data. 
online resources about CAM and CAM-related adverse effects. This list of recommended resources can thereby serve as a useful reference for clinicians, researchers, and patients.

Keywords: Adverse events, Complementary and alternative medicine, eHealth, Online resources, Herbal therapies, Herb-drug interactions, Quality assessment, Side effects

\section{Background}

Online resources that provide information about adverse interactions or side effects associated with complementary and alternative medicine (CAM) are paramount for obtaining updated and complete information for both clinicians who encounter patients who inquire about CAM, as well as researchers with an interest in this area [1]. CAM is an umbrella term used to describe a wide range of therapies that include a large number of modalities and which originate from different parts of the world. A plethora of widely-used terms and definitions for CAM exists [2], however, the National Center for Complementary and Integrative Health $(\mathrm{NCCIH})$ defines a non-mainstream practice used together with conventional medicine as "complementary", and a nonmainstream practice used in place of conventional medicine as "alternative". Though adverse events and side effects can arise from the use of a wide-range of CAM therapies, the majority of them involve natural products, such as dietary supplements and herbal therapies [3, 4]. It is estimated that $80 \%$ of the population internationally uses natural products [5], with that increasing up to $95 \%$ in developing countries [6]. While limited data exists regarding the prevalence of adverse events associated with dietary supplements, it has been found that the rate of natural product users who report adverse effects is approximately $12-14 \%$ in Canada and the United States $[4,7]$. As such, clinicians and researchers have a responsibility to utilize CAM-related electronic resources that are accurate, up-to-date, and of high quality.

Since the advent of the internet, many online resources have since been created to serve this purpose, however, many have since ceased to exist or to be updated. A recent scoping review identified numerous reviews that have been published providing overviews or summaries of CAM-related healthcare or research resources. However, the most recent reviews providing CAM information in general were published approximately $10-20$ years ago and are undoubtedly obsolete to at least some degree [8-15]. Additionally, with the exception of Boehm et al's review, the other CAM-related reviews did not employ a systematic search strategy, and therefore likely do not provide a comprehensive list of resources, arguably even at the time of publication [8-11].

Today, there exists more information on the internet about CAM than ever before; a search for "complementary and alternative medicine" on Google alone yields 119 million search results as of May 2020 [16]. This vast abundance of such online information is not regulated for quality, nor is it formally assessed in the literature using a validated tool, such as the DISCERN instrument [17]. This lack of quality regulation makes it challenging and time-consuming for even experienced clinicians and researchers to evaluate for quality when searching for information about CAM. Perhaps even more disadvantaged are patients who often do not have the expertise to appropriately evaluate online clinical content, and are likely to consult the internet for answers in the moment of experiencing a CAM-related adverse event or side effect. Over recent years, CAM use has become increasingly more popular among patients [18]. Amongst healthcare providers, a greater acceptance of CAM has ensued, coupled with the recognition that there is a need for clinicians to increase their knowledge of CAM [19, 20]. For these reasons in conjunction with a dramatic rise in interest in conducting CAM studies among researchers $[2,21]$, a more recent update incorporating a systematic search is warranted. Thus, the purpose of this study is to summarize and assess the content quality of web-based online resources providing information about adverse interactions or side effects associated with CAM [22] in order to provide clinicians and researchers with a comprehensive list of resources containing information on this topic.

\section{Methods \\ Approach}

A systematic search and scoping review published by $\mathrm{Ng}$ et al. in 2020 was undertaken to answer the following research question: "What eHealth technologies are assisting in identifying potential (1) adverse drug interactions with CAM, (2) adverse CAM-CAM interactions or (3) standalone CAM adverse events or side effects?" [22]. Based on our understanding of this existing knowledge gap, we elected to present our findings in the format of summaries outlining what each resource offers the user, along with DISCERN instrument quality assessments of each resource allowing clinicians and researchers to quickly choose a suitable resource for their needs. 


\section{Step 1: Selecting eligible online resources}

The research questions for the present study were as follows: "What web-based online resources are typically available and accessible to clinicians that contain patient information about adverse interactions or side effects associated with CAM?" and "What is the quality of patient health information provided by these aforementioned resources?". For the purpose of this study, we considered an operational definition of CAM inclusive of the following 5 categories of therapies: whole medical systems; mind-body medicine; biologically based practices not usually used in conventional medicine; manipulative and body-based practices; and energy medicine [23]. While we acknowledge that the large majority of adverse interactions or side effects associated with CAM likely pertain to biologically-based practices not usually used in conventional medicine, such as dietary and herbal supplements, we did not limit our definition of CAM to this single category. Instead, we also considered other CAMs such as chiropractic or acupuncture, which also have standalone adverse interactions or side effects, in addition to contraindications with various conventional therapies. All eligible eHealth technologies derived from $\mathrm{Ng}$ et al's scoping review were re-assessed by JYN and $\mathrm{VM}$, and only deemed eligible for the purpose of the current study if they were a web-based online resource that presented information on potential interactions, adverse effects, or safety risks of CAM. eHealth technologies were excluded if they were not web-based online resources or were online resources that met one or more of the following criteria: exclusively mobilebased online resources; online resources only providing information about the biochemical properties, molecular structure, or chemical compositions of CAMs (i.e. herbs, traditional Chinese medicines); or online resources that contained dead weblinks. It should be clarified that the present study did not seek to identify nor assess the quality of websites typically assessed by patients or members of the public, hence we did not search commonly used search engines such as Google.

Next, JYN and VM data extracted the following information from all included online resources: name of online resource; eligible article(s) from which it was referenced; online resource URL; year established; availability of the online resource; type of developer; whether the online resource contained information on only CAM or CAM and conventional therapies. Additionally, we provide a brief summary of each included online resource that we present in this article's "Results" section.

\section{Step 2: Assessing online resource content quality}

The content quality of all eligible online resources was assessed using the DISCERN instrument. While a variety of instruments exist to assess health information, we selected DISCERN as it is one of the most widelyaccepted, reliable, and validated instruments. It contains a series of 16 questions that are designed to assess the quality of consumer health information found offline or on the Internet using a rating scale of 1-5 for each question. The instrument was developed by a team of researchers from the University of Oxford and the British Library. Designed for use by both healthcare professionals and the general public, the instrument is publicly available on the web (www.discern.org.uk) [17].

Prior to assessing all online resources, all three authors participated in a pilot assessment of a subset of online resources using the DISCERN assessments. After independently applying the DISCERN instrument, the authors met to discuss discrepancies in their scores. Disagreements were resolved by discussion, and in the case that consensus could not be reached, a majority vote was used to assign rating scores. Subsequently, VM and HT independently assessed each included online resource using DISCERN, then all three authors met to discuss scores and resolve discrepancies. We made every attempt to assess subscription-based online resources; if we did not have access to them through our university library system, we contacted the company, organization or individual that produced the online resource requesting trial access for the purpose of this study. Acknowledging that the DISCERN instrument was originally designed to assess the patient health information of a treatment choice (and not specifically the information pertaining to adverse events and side effects, though this is undoubtedly a large component of whether a treatment choice would be deemed suitable or not), we conducted a general quality assessment for each eligible online resource, where we looked at a large enough proportion of CAMrelated patient information surrounding adverse events and side effects across each online resource to provide a holistic DISCERN score. Lastly, we acknowledge that while some online resources only contained CAM-specific information, others provided additional information about non-CAM (i.e. conventional medicine). To standardize our quality assessment, we only used the DISCERN instrument to assess the quality of CAM-specific information provided by all resources. Thus, we provide a quality assessment for resources that a clinician may want to consult when providing a patient with CAMspecific information. We did not make a judgement of quality associated with the non-CAM sections of any resources. 


\section{Step 3: Analysis of DISCERN results}

DISCERN ratings from VM and HT were combined by calculating the mean values of the author's independent DISCERN scores. The sum of these combined scores were used to calculate the total DISCERN scores and standard deviations for each online resource. The average scores were also calculated for each DISCERN question across all online resources, as well as the standard deviation of the overall score assigned in question 16.

\section{Results}

\section{Search results (Fig. 1)}

Forty-one articles from the $\mathrm{Ng}$ et al. scoping review were assessed for eligibility in the present study, whereby all articles referenced an electronic tool or resource containing information about CAM and CAM-related adverse effects. Of these 41 articles, 20 articles were eliminated because they developed or referenced (1) other eHealth technologies that were not web-based online resources $(n=13)$, or (2) online resources that were entirely mobile-based, predominantly biochemistry focused or unavailable $(n=7)$. Thus, a total of 21 articles were found to be eligible and included in the present study [8-14, 24-37]. A PRISMA diagram is provided in Fig. 1 of "Appendix 1".

\section{Findings from eligible articles}

A compiled list of the 21 eligible articles and characteristics are provided in Table 1 of "Appendix 2". The list of eligible articles includes both primary research articles $(n=9)$ and review articles $(n=12)$. Primary research articles were designed to develop $(n=3)$ or evaluate $(n=6)$ one or more online resources containing CAMspecific information, while all secondary articles $(n=12)$ reviewed eHealth technologies and online resources containing CAM-specific information that met our research criteria. Articles were published from 2001 to 2019 in the United States $(n=14)$, UK $(n=2)$, China $(n=2)$, Singapore $(\mathrm{n}=1)$, Italy $(\mathrm{n}=1)$, Greece $(\mathrm{n}=1)$ and Canada $(\mathrm{n}=1)$.

\section{Online resource characteristics}

Twenty-three web-based online resources containing CAM safety information were extracted from the eligible articles. Six of these online resources were dedicated entirely to CAM, while 17 online resources provided information on CAM as well as other conventional therapies. For many online resources, it was difficult to determine the exact date of establishment, however online resources were established as early as 1970 to as late as 2007. At least 11 online resources were established prior to 2015. All online resources were found to have been used in some form of context outside the author's study, most often having been referenced in other papers in the literature. All online resources were available for the public to access and were either entirely free $(n=14)$, required a paid subscription $(\mathrm{n}=8)$, or required a partial subscription $(\mathrm{n}=1)$. Characteristics of all included online resources are detailed in Table 2 of "Appendix 2".

\section{Summaries of included online resources}

Summaries for the 23 online resources are provided below:

\section{About Herbs}

Website: https://www.mskcc.org/cancer-care/diagnosistreatment/symptom-management/integrative-medicine

About Herbs is an online database managed by the Memorial Sloan Kettering Cancer Center. The database provides herb and dietary supplement monographs for patients and caregivers, as well as professional monographs for healthcare providers.

Monographs for patients/caregivers list warnings and side effects. Monographs for healthcare professionals list adverse reactions, contraindications, warnings and interactions.

\section{American Botanical Council}

Website: https://abc.herbalgram.org/site/PageServer

The American Botanical Council (also known as "Herbal Medicine Institute") is a non-profit organization that provides information to consumers, researchers and health professionals on herbal medicines. The website includes: ABC Clinical Guide to Herbs (online searchable database of monographs, clinical overviews and patient information sheets); HerbalGram (online journal publications); HerbClip (database of videos that summarize and critically review research, publications and marketing material of medicinal drugs); Herbal MediaWatch; (articles from various media sources regarding health and medicinal plants); product-specific and botanical ingredient monographs; HerbMed (online database of resources, articles and summaries of various herbal drugs); Adulteration Program (to provide education and prevent the ingredient and product adulteration of herbal and dietary supplements); and a medicinal plant identification database.

Monographs and drug profiles on HerbMed list adverse effects and toxicity, interactions, contraindications and relevant evidence from clinical trials about product safety. 


\section{Caremark Drug Interactions}

Website: https://cpref.goldstandard.com/inter .asp? $\mathrm{r}=8084$

Copyrighted through Gold Standard, Caremark Drug Interactions is a web-based database of drug interactions. Reports can be generated for potential interactions between prescription drugs, herbs, vitamins, over the counter drugs, caffeine, grapefruit juice, food, tobacco, alcohol and enteral feedings.

The resource contains a searchable drug interaction checker tool that provides alerts for potential drug interactions. The level of severity and possible side effects are listed for each interaction. The website indicates drugs, supplements or drug combinations that require a user to contact their healthcare provider.

\section{Clinical Pharmacology (through Clinical Key)}

Website: https://www.clinicalpharmacology.com/

Clinical Pharmacology is a drug information resource that is powered by Clinical Key and owned by Gold Standard. The resource contains a database of monographs for prescription drugs, over the counter products, herbal medicines and nutritional supplements. Other features include: IV compatibility tests; drug product comparisons; patient education handouts; drug product information; drug interaction reports; clinical decision support tool; drug IDentifier; resources and educational modules.

The resource contains a searchable drug interaction checker tool that generates interaction reports. Drug monographs provide information on contraindications, warnings, adverse effects and interactions with other drugs, food or supplements.

\section{Drug Information (formerly DrugDigest)}

Website: https://www.express-scripts.com/medco/ consumer/ehealth/druginfo/dlmain.jsp?WC $=\mathrm{N}$

Drug Information (formerly known as DrugDigest), is a web-based, searchable database that provides information on medications, herbal medicines and dietary supplements. The database indexes various brands, dosages and forms of a drug or supplement. Drug summaries include frequently asked questions which outline the benefits, risks and guidelines for consumers. Several drugs are indexed in the database; however, a large proportion do not have information available.

Drug summaries list potential side effects as well as other more serious adverse effects that warrant medical attention. Warnings and risks are listed which include: warnings for pregnant or breastfeeding women; interactions with other drugs or substances; instructions in cases of missed dosages; items that should be discussed with a healthcare provider before starting a drug.

\section{Drug Product Database}

Website: https://www.canada.ca/en/health-canada/servi ces/drugs-health-products/drug-products/drug-produ ct-database.html

The Drug Product Database is maintained by Health Canada and contains a searchable database of drugs authorized for sale in Canada. The database includes: availability of drugs on the market; product monographs for human drugs; labels for animal drugs; tables containing product and monograph safety updates. The database indexes drugs of various statuses including those have been approved, marketed or cancelled. A small proportion of drugs in the database have online product monographs available.

The website provides a table for each month that lists safety updates made to monographs in one or more of the following areas: contraindications; warnings and precautions; adverse reactions; drug interactions; dosage and administration; overdosage; consumer information. When a drug product monograph is available in the database, it includes information for both healthcare professionals and consumers. The content of monographs vary but commonly provide information on adverse reactions, drug interactions, contraindications, warnings and precautions.

\section{Drugs.com}

Website: https://www.drugs.com/

Drugs.com is a web-based resource that provides drug information to healthcare professionals and patients. The resource includes: database of consumer leaflets and professional drug monographs; drug interaction checker; FDA alerts; news centre, drug approval updates, clinical trials; pill identifier; dosage guides; drug pricing guides; symptom checker; disease reference summaries; health education videos. Drugs.com is also offered as a mobile resource, though this was not evaluated for quality in the present study.

The searchable drug interaction checker tool provides alerts for potential drug interactions. Alerts are provided for drugs, alcohol, food and disease interactions. Side effects and level of interaction severity are provided. A consumer and healthcare professional version of the interaction description are provided for each alert.

\section{Electronic Medicines Compendium}

Website: https://www.medicines.org.uk/emc/

The electronic medicines compendium (EMC) is an online resource containing information about drugs licensed for use in the United Kingdom. All website 
content is reviewed and approved by UK or European government agencies. The website includes: searchable database of Summaries of Product Characteristics (SmPC) for health professionals; Patient Information Leaflets (PILs); Risk Minimisation Materials (RMMs); safety alerts; side effect reporting tool through Yellow Card.

Contraindications, special warnings, precautions for use, interactions, incompatibilities, side effects, adverse reactions and overdose precautions are listed in the SmPC and PILs. The side effect reporting tool allows patients and healthcare providers to report suspected problems to the UK government of incidents or side effects that may be associated with a drug or supplement. Alert cards are available for drugs that outline signs and symptoms of a serious reaction. Risk Minimisation material outline the risk factors for a drug and provide information for clinicians to promote the safe use of a drug.

\section{Epocrates (Plus or pro)}

Website: https://online.epocrates.com/

Epocrates is a web-based resource which includes: database of drug monographs; index of drug interactions; therapeutic tables; interaction checker. Epocrates is also offered as a mobile resource, though this was not evaluated for quality in the present study.

Multicheck Drug Interaction Checker is a searchable drug interaction checker tool that reports on potential drug interactions and their level of severity. The resource also includes a built-in feature to search for drugs that may have caused a particular side effect in a user. Monographs include a list of drug interactions, safety/monitoring information, contraindications, cautions and adverse reactions.

\section{Herb-Drug Interactions, NCCIH Clinical Digest}

Website: https://nccih.nih.gov/health/providers/digest/ herb-drug

This digest contains an index of 8 herbs with evidencebased information obtained from clinical studies. Each summary provides a short description of the common uses for the herb and lists potential interactions with other substances.

Each summary includes a brief description of potential herb-drug interactions. When available, clinical trials and studies that investigate interactions with the herb are listed. An overview of safety warnings or potential side effects of the herb are provided.

\section{Herbs at a Glance}

Website: https://nccih.nih.gov/health/herbsataglance. htm
Herbs at a Glance is a website that presents an index of fact sheets for a variety of herbs. Fact sheets provide information including: general background and overview; safety information; potential side effects; evidence and information from scientific studies; links to other resources.

Fact sheets provide warnings and safety information about the herb. When applicable, drug interactions are listed.

\section{HIV Drug Interactions}

Website: https://www.hiv-druginteractions.org/checker

HIV Drug Interactions is a web-based resource developed by the University of Liverpool to provide healthcare professionals, patients and researchers with education on HIV drug interactions. The website features: printable resources such as interaction charts or treatment selectors; fact sheets; video lectures; HIV drug interaction checker.

The searchable drug interaction checker tool provides alerts for potential interactions between drugs or CAM products used to treat HIV. Alerts outline the level of severity, quality of evidence and a summary of the interaction. PDF printouts of interaction tables are available. Drug fact sheets often include cautions regarding prescribing and dosage.

\section{IBM Micromedex (includes DrugDex, Drug-Reax, AltMedDex)}

Website: https://www.micromedexsolutions.com/home/ dispatch/ssl/true

IBM Micromedex is an online resource for health professionals that includes; drug interaction checker; IV compatibility; drug comparison tool; dosing tools and calculators; searchable drug, disease and toxicology database of monographs; Carenotes (printable reports for patient education). Micromedex is also offered as a mobile resource called mobileMicromedex, though this was not evaluated for quality in the present study.

The searchable drug interaction checker tool provides alerts for potential interactions between drugs, herbs/ supplements, food, alcohol, tobacco, pregnancy/lactation and allergies. Interaction reports include a short summary of the warning, onset, level of severity, available documentation, clinical management guide and the probable mechanism. Drug profiles outline toxicology, adverse effects, warnings and potential interactions.

\section{Lexi-Natural (includes LexiComp)}

Website: https://webstore.lexi.com/Store/Individual -Databases/Lexi-Natural-Products

Lexicomp is an online drug information database and resource for healthcare professionals and patients. The resource includes: drug monographs; clinical calculators; 
patient handouts; pill identification. Briggs Drugs in Pregnancy and Lactation contains drug monographs with information specifically for pregnant and lactating users. Lexi-natural is an extension of Lexicomp which provides information on over 415 natural products. Lexicomp is also offered as a mobile resource, though this was not evaluated for quality in the present study.

Professional monographs provide information on contraindications, interactions, toxicology, adverse reactions and pregnancy and fetal risk summaries. Patient education handouts provide information on precautions, side effects and signs that indicate the patient should contact their healthcare provider. Briggs monographs list evidence for risks to fetus and breastfeeding.

\section{MedicinesComplete (includes Herbal Medicines; formerly known as the British National Formulary)}

Website: https://about.medicinescomplete.com/publi cation/herbal-medicines/

Developed by the Royal Pharmaceutical Society, MedicinesComplete is an online resource of the British National Formulary (BNF). The resource includes: database of drug monographs; dosing information; drug interaction checker; professional development content; research and case studies.

The resource provides searchable information on drug interactions, adverse effects, safety warnings and contraindications. Stockey's Drug Interactions module provides reports on drug-drug, drug-herb and drug-food interactions. The Martindales adverse drug reaction checker provides severity ratings and support for healthcare providers to manage patients who present with adverse drug reactions.

\section{Medscape}

Website: https://www.medscape.com/

Medscape is a web-based clinical resource tool for healthcare professionals. The resource includes: medical news articles; educational tools (clinical briefs, patient cases, quizzes, e-learning courses, videos and other educational activities for CME credits); patient handouts; drug interaction checker; pill identifier; clinical calculators; health directories; interactive diagnostic modules; clinical guidelines; journal articles through MedLine; drug database. The database contains monographs on prescription drugs, over-the-counter products and herbal supplements. Medscape is also offered as a mobile resource, though this was not evaluated for quality in the present study.

Drug monographs list adverse effects, warnings and contraindications. The searchable drug interaction checker provides alerts for potential drug and/or CAM interactions. Interaction alerts outline the level of severity and whether an alternative therapy should be used.

\section{Merck Manual}

Website: https://www.merckmanuals.com/en-ca/

Merck Manual offers an online version of the hardcopy Merck Manual with 2 separate editions for healthcare professionals and consumers. Both editions of the web-based resource include: searchable database of drug monographs; news; information profiles for diseases and health topics; quizzes, podcasts and other resources. The Health Professional edition also includes: case studies and training materials; procedural videos; clinical calculators and other clinical resources. In addition, the consumer edition includes: index of symptoms; index of information for different medical emergencies.

Health Professional drug monographs list warnings/ precautions, contraindications, adverse reactions, drug interactions, safety issues, allergy and idiosyncratic reactions. Patient education monographs list possible side effects and possible drug interactions.

\section{National Cancer Institute}

Website: https://www.cancer.gov/about-cancer/treat ment/cam

This website uses NCI's Physician Data Query (PDQ) database to provide information on CAM drugs that are used to treat cancer patients. Each drug contains a separate summary for patients and health professionals. Both patient and healthcare professional drug summaries provide general information about the treatment as well as clinical trials and evidence from the scientific literature.

When sufficient evidence is available, drug summaries list potential interactions with other cancer drugs. Adverse effects are included in both the patient and healthcare professional summaries.

\section{Natural Medicines (formerly Natural Medicine Comprehensive Database (NMCD) and Natural Standard Database (NSD))}

Website: https://naturalmedicines.therapeuticresearch. com/

Natural Medicines is a web-based resource that includes: interaction checker; effectiveness checker; nutrient depletion, pregnancy and lactation checker; adverse event checker. Natural Medicines includes several sub-databases containing information on food, herbs and supplements, herbal combinations, drug manufacturers, sports medicine, health and wellness topics and comparative effectiveness. Natural Medicines is also offered as a mobile resource, though this was not evaluated for quality in the present study. 
The searchable drug interaction checker tool provides interaction alerts which include the severity, likelihood of occurrence and level of significance for the potential interaction. Both the professional monograph and patient handout include safety concerns and precautions, interactions with drugs, herbs, food or lab. The professional monographs also provide information on toxicology and adverse effects.

\section{OncoRx Database}

Website: https://www.onco-informatics.com/oncorx/

Onco Rx is a web-based and mobile database of interaction information for oncology drugs, chemotherapy regimens and CAM products. Onco Rx is also offered as a mobile resource called OncoRx MI, though this was not evaluated for quality in the present study.

The database provides information on the pharmacokinetic and pharmacodynamic properties of oncology specific drug-drug or CAM-drug interactions. Drug interaction reports are comprised of theoretical and evidence-based information.

\section{PEPID Drug Information Database}

Website: https://www.pepid.com/

PEPID Knowledgebase is a web-based database hosted through PEPID Connect. Features of PEPID Connect include: Drug interaction checker; drug-allergy checker; pill identification; IV Compatibility tool; lab manuals; clinical calculators; drug database; differential diagnosis and symptom checker; news and alerts; PEPID PGx pharmacogenomic tool. PEPID is also offered as a mobile resource, though this was not evaluated for quality in the present study.

The searchable drug interaction checker tool provides interaction monographs which outline the mechanism of interaction, effects, level of concern and recommended actions. Drug monographs outline contraindications, cautions, interactions and adverse drug reactions.

\section{RxList (owned by WebMD)}

Website: https://www.rxlist.com/script/main/hp.asp

RxList is a web-based resource that includes: health and drug news; symptom checker; drug interaction checker; articles on diseases and conditions; medical dictionary; media (quizzes, slideshows and images); pill identifier; drug databases. The website contains a database of monographs on vitamins, herbs and dietary supplements. Monographs contain a description of the drug, evidence for effectiveness, how the drug works, warnings, interactions and dosing recommendations.

Monographs list interactions, safety concerns, warnings and precautions. The searchable drug interaction checker tool provides alerts for potential interactions between 2 or more drugs or supplements. Interaction alerts are categorized according to level of seriousness and include separate sections for patients/caregivers and healthcare professionals.

\section{RxMed}

Website: https://www.rxmed.com

RxMed is a website for family physicians and patients that includes: database of disease monographs for common illnesses; database of monographs on prescription medication, herbs, vitamins and dietary supplements. Herbal monographs contain general descriptions, composition, medicinal uses, connected diseases and safety information.

Safety information is provided in the herbal monographs which include adverse side effects, contraindications and precautions.

\section{DISCERN Instrument Ratings}

DISCERN scores presenting the means across two assessors (VM, HT) for 19 online resources are listed in Table 3 of "Appendix 2". Of the 23 eligible online resources, 4 online resources (Onco-RX, Clinical Pharmacology, Epocrates and MedicinesComplete) were not accessible as they required paid subscriptions and were not available through the author's institutions. The authors contacted the respective online resources to request access for the purposes of this study. Representatives from the online resources either did not reply or advised that they could not provide trial access. For this reason, these online resources were not assessed and are not included in Table 3 of "Appendix 2".

Notably, none of the 19 online resources received a perfect score (5) on all 15 DISCERN questions. Evidently, most online resources received a poor rating in at least one question with $84.21 \%$ of resources receiving a score of 1 in at least 1 of the 15 DISCERN questions. Total scores for DISCERN ratings ranged from 33.0 - 68.50, with an average total score of $56.13(S D=10.25)$ out of a maximum score of 80 . The 3 online resources receiving the highest total DISCERN score were Micromedex (68.50), Merck Manual (67.50) and Drugs.com (66.50). The 3 online resources that received the lowest total DISCERN scores were Drug Information (33.00), Caremark Drug Interactions (42.50) and HIV Drug Interactions (43.00).

For each DISCERN question, mean scores from all online resources were calculated. The 4 questions that received the highest mean scores included whether the risks were described for each treatment $(M e a n=4.66$, $S D=0.73)$, whether the aims were clear $($ Mean $=4.58$, $S D=0.99)$, whether the source achieved those aims $($ Mean $=4.58, S D=1.03)$, whether the website referred 
to areas of uncertainty (Mean $=4.58, S D=0.63)$ and if the resource was relevant (Mean $=4.42, S D=0.75)$. The questions that received the lowest mean scores referred to discussion about no treatment being used $($ Mean $=1.29, S D=0.75)$, how treatment choices would affect quality of life (Mean $=2.00, S D=1.09$ ), and discussion of whether there is more than one possible treatment choice $($ Mean $=2.97, S D=1.25)$.

Notably, some online resources including Drug Information and Drug Product Database, indexed many drugs that did not contain any content or did not have a monograph available. As a result, the DISCERN scores were considerably lower for these online resources, for both the overall mean score and ratings for individual questions. The absence of content for these drugs may be due to a variety of potential reasons; the product may have been discontinued or taken off the market, inadequate information is available, or the online resource is not up to date. However, it was often the case that when monographs were available, they contained comprehensive and high-quality content. Nevertheless, the ratings were significantly lower for these online resources because the information provided was not consistent among all treatments.

\section{Trends identified across resources assessed}

After observing the results from the DISCERN assessments, the authors identified 3 main trends across the resources assessed:

\section{No treatment choice}

Question 12 in the DISCERN instrument assesses the degree to which a resource provides an explanation of what patients could expect if they did not undergo treatment. The majority of the online resources in this study scored poorly on this question, with 15 of the 19 (78.95\%) online resources receiving a score of 1 out of 5 on this question. Additionally, none of the online resources received a perfect score of 5 on this question. Most resources discussed other aspects of CAM drugs but did not make any acknowledgement or provide discussion regarding the alternative option of no treatment. Our results suggest that it is not yet common practice for health resources to discuss this facet.

\section{Treatment effect on quality of life}

Question 13 in the DISCERN instrument assesses whether a resource describes how a treatment would affect the overall quality of life of the user. Of all online resources assessed, 12 out of 19 online resources (63.16\%) received a score of 2 or lower on this question. Few resources provided information regarding how treatment choices may impact a patient's day-to-day activities and relationships with family, friends, and careers. It does not appear to be common practice for websites and online resources to discuss these aspects for CAM treatments.

\section{Safety and adverse effect information}

Question 11 in the DISCERN instrument assesses whether a resource discloses the risks of each treatment. This question received a mean score of $4.66(S D=0.73)$ across all online resources, with 17 out of 19 (89.47\%) online resources receiving a score of a 4 or higher on this question. These results were unsurprising, as our inclusion criteria required that resources provide information on interactions or adverse effects. Safety information reported by online resources include risks, warnings, precautions, potential side effects, or potential interactions. This information is often disclosed in a product monograph or as an alert from an interaction checker tool. Interaction checkers were provided by 12 out of 19 (63.16\%) online resources and provide a tool for the user to search for potential interactions between drugs, CAM, food, alcohol and other substances. DISCERN does not assess the accuracy or comprehensiveness of the content, therefore it cannot be certain that the online resources include complete and extensive lists of all potential risks of CAM treatments. However, our results suggest that all online resources in this study provide information on the safety and adverse effects of CAM to some degree.

\section{Discussion}

The aim of this study was to identify web-based online resources providing patient health information about adverse interactions or side-effects associated with CAM, and conduct a quality assessment using the DISCERN instrument. While some of these resources require paid subscriptions, the majority are freely accessible to the public and can be easily found via a Google search. With such easily accessible information, the consequence is the ease at which false, misleading or inaccurate information can be disseminated to the public. This elicits several concerns for the safety and well-being of consumers, especially amidst the tendency for patients to trust health information found on the Internet [38, 39], as well as perceive CAM as safe, thus feeling the need to take less precaution [40]. In addition, healthcare providers and researchers may use these online resources to gather information about CAM treatment choices and management plans for patients. To address these longstanding concerns and needs, this study provides healthcare professionals, researchers and patients with a list of resources, evaluated for quality, which could be used to compile comprehensive and evidence-based information about interactions or adverse effects associated with CAM. This was achieved by using the DISCERN 
instrument as a quality appraisal tool for various online resources containing CAM-specific information. Results from the assessment exhibit a considerable range in quality of information across online resources.

\section{Information on treatment choices: quality of life and risk of no treatment}

There were 2 questions that most online resources scored poorly on for quality. The first was in regards to the quality of discussion about what a patient could expect if they delay or refrain from the treatment entirely. It may be argued that this question is outside of the scope and intent of CAM resources, which primarily aim to present the available information concerning the use of CAM drugs. However, it is important for healthcare providers and patients to be aware of the potential benefits and risks that a patient may experience if they make the decision to forgo CAM or other treatments for their condition. Providing further information on this subject would facilitate more informed and holistic management strategies for healthcare providers and consumers. Online resources also consistently scored poorly on the question associated with the discussion about how a treatment may affect a patient's quality of life. Understanding these potential impacts may change a patient's choice in treatment or disease management, therefore, it is important that this information be communicated to the patient. The inclusion of these components does not appear to be common practice for many online resources.

\section{Target audiences}

While the identified online resources containing CAMspecific information are generally designed to be accessed and used by clinicians, the users of this information includes a wider range of individuals, inclusive of researchers, patients and the general public. As the needs of these end-users will vary, content in the online resources should be reflective of the intended users. Healthcare providers require additional information that is irrelevant or too complex for the general public. For example, information on pharmacology and dosing instructions would be imperative for a healthcare provider to incorporate into their clinical practice and treatment plans. On the other hand, this information may not be required or appropriate for the general public. Additionally, there is a tendency for health information on the Internet to be written at a level that is too complex for a large proportion of consumers to comprehend, thus increasing the risk of physical, emotional or financial harm associated with content that is misunderstood or misinterpreted by patients and their families [41, 42]. Resources such as Merck Manual, About Herbs, Lexicomp, National Cancer Institute and Electronic Medicine
Compendium were found to provide separate reading materials for both healthcare professionals and patients. Online resources and websites are either separated entirely or contain 2 versions of monographs for each treatment, thus ensuring that CAM information is delivered to the intended audience at an appropriate reading level. A future study may evaluate the readability of online resources containing CAM-specific information to compare reading levels with target audiences.

\section{Strengths and limitations}

A significant strength of this study includes the fact that the results from the systematic search strategy in $\mathrm{Ng}$ et al's (2020) scoping review were used to identify eligible online resources containing CAM-specific information for the present study. This methodological approach allowed us to extract a comprehensive and extensive list of online resources that met our research criteria. Additionally, all three authors participated in a pilot assessment of a subset of online resources prior to the independent assessment of all online resources by two authors, therefore increasing the validity of the ratings and associated analyses.

Given that we did not assess the accuracy of the information in the online resources, this may be noted as a limitation to the study. However, this form of validation is outside of the scope of the DISCERN instrument. Assessing the accuracy of information would require the authors to research and verify the evidence and claims found in each resource, which reflects a warranted future direction. An additional challenge involved the fact that the DISCERN instrument was designed to assess the quality of consumer health information about treatment choices, while the focus of this study was on the quality of patient information about adverse interactions or side effects associated with CAM. To our knowledge, no instrument exists that specifically assesses this type of information, thus we deemed the DISCERN instrument to be the most suitable given that adverse interactions and side effects make up a large component of the patient information surrounding treatment choices. Additionally, only studies published in the English language were includd in this study. Likewise, only online resources written in the English language were assessed, thus excluding other potentially relevant online resources that were written in a non-English language or referenced in a article published in a non-English language. Another limitation of the study is that 4 of the eligible online resources were not assessed with DISCERN. Despite our best efforts, we were unable to obtain free access to these online resources. After reaching out to the developers or companies of the online resources to request access, 
we either received no response to our request or were advised that a trial subscription could not be granted.

\section{Conclusion}

Informed by the systematic search conducted in a previously published scoping review, this study provides a summary and quality assessment of existing web-based online resources that provide information on CAM and the associated adverse interactions or side effects. The present study provides a comprehensive list of webbased online resources containing CAM-specific information that are readily available on the internet. Given the prevalence of CAM use in the population and the abundance of online resources available on the web, this justified the need for a content quality assessment of these online resources. To the best of our knowledge, our study is the first to use the DISCERN evaluation instrument to provide an overview of the content quality of these online resources. After reviewing the results of the DISCERN assessments, we have outlined recurrent gaps in the quality of these web-based online resources. The summaries and quality assessments of each online resource, along with a list of recommended resources, can benefit healthcare providers, researchers, and patients in selecting suitable web-based resources to obtain high-quality, evidence-based CAM information.
Abbreviation

CAM: Complementary and alternative medicine.

\section{Acknowledgements}

We gratefully acknowledge librarian Laura Banfield for providing guidance in constructing the search strategy, and Maryam Mooghali for assistance with the search results screening.

\section{Authors' contributions}

JYN: conceptualized and designed the study, collected the data, interpreted and analysed the data, drafted the manuscript, and gave final approval of the version to be published. VM: collected the data, interpreted and analysed the data, provided contributions and critically revised the manuscript, and gave final approval of the version to be published. HT: collected the data, interpreted and analysed the data, provided contributions and critically revised the manuscript, and gave final approval of the version to be published. All authors have read and approved the manuscript.

\section{Funding}

This study was not funded.

\section{Availability of data and materials \\ All relevant data are included in this manuscript.}

\section{Ethics approval and consent to participate}

This study involved a systematic search, summarization and quality assessment of the literature only; it did not require ethics approval or consent to participate.Consent for publicationNot applicable.

\section{Competing interests}

The authors declare that they have no competing interests.

\section{Appendix 1}

See Fig. 1.

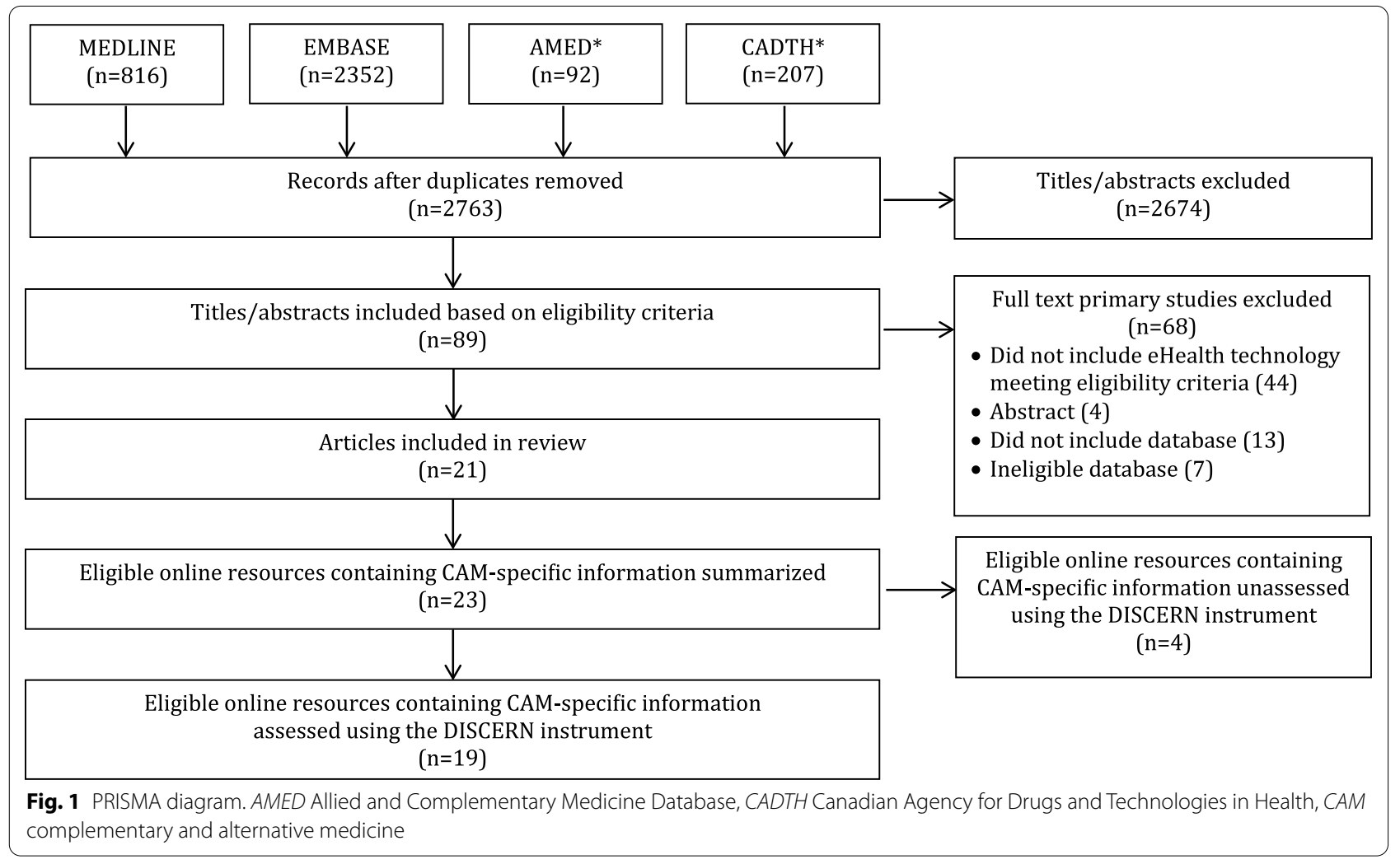




\section{Appendix 2}

See Tables 1, 2 and 3.

Table 1 Eligible article characteristics $(n=21)$

\begin{tabular}{|c|c|c|c|c|}
\hline References & Article title & Study country & Study design & Article type \\
\hline Allais et al. [8] & $\begin{array}{l}\text { Access to databases in complementary } \\
\text { medicine }\end{array}$ & Italy & Review of medical information resource(s) & Review \\
\hline Archer et al. [24] & $\begin{array}{l}\text { Development of an alert system to detect } \\
\text { drug interactions with herbal supplements } \\
\text { using medical record data }\end{array}$ & USA & Development of alert system prototype & Original Research \\
\hline Boddy et al. [25] & $\begin{array}{l}\text { Review of reliable information sources } \\
\text { related to integrative oncology }\end{array}$ & UK & Review of medical information resource(s) & Review \\
\hline Boehmer et al. [26] & $\begin{array}{l}\text { Evaluating the value of a web-based natural } \\
\text { medicine clinical decision tool at an aca- } \\
\text { demic medical center }\end{array}$ & USA & $\begin{array}{l}\text { Evaluation of web-based clinical decision } \\
\text { tool }\end{array}$ & Original Research \\
\hline Clauson et al. [27] & $\begin{array}{l}\text { Clinical decision support tools: Personal } \\
\text { digital assistant versus online dietary sup- } \\
\text { plement databases }\end{array}$ & USA & $\begin{array}{l}\text { Review and evaluation of databases and } \\
\text { personal digital assistants }\end{array}$ & Review \\
\hline Faubert et al. [28] & $\begin{array}{l}\text { A pilot study to compare natural health } \\
\text { product-drug interactions in two data- } \\
\text { bases in Canada }\end{array}$ & Canada & Evaluation of databases & Original Research \\
\hline Fischer et al. [29] & $\begin{array}{l}\text { Complementary and alternative medical } \\
\text { reference software for personal digital } \\
\text { assistants: Evidence of clinical applicability }\end{array}$ & USA & Evaluation of databases & Original Research \\
\hline Fitzpatrick et al. [30] & Natural standard database & USA & Review of medical information resource(s) & Review \\
\hline Gregory et al. [31] & $\begin{array}{l}\text { Characterization of complementary and } \\
\text { alternative medicine-related consultations } \\
\text { in an academic drug information service }\end{array}$ & USA & $\begin{array}{l}\text { Analysis of complementary and alternative } \\
\text { medicine drug information consultations }\end{array}$ & Original Research \\
\hline Jackson [9] & $\begin{array}{l}\text { An overview of information resources for } \\
\text { herbal medicinals and dietary supplements }\end{array}$ & USA & Review of medical information resource(s) & Review \\
\hline Jackson et al. [10] & $\begin{array}{l}\text { Resources for information on herbal medici- } \\
\text { nals and dietary supplements }\end{array}$ & USA & Review of medical information resource(s) & Review \\
\hline Kiefer et al. [12] & $\begin{array}{l}\text { Finding information on herbal therapy: A } \\
\text { guide to useful sources for clinicians }\end{array}$ & USA & Review of medical information resource(s) & Review \\
\hline Meyer et al. [13] & $\begin{array}{l}\text { Evaluation of herbal-drug interaction data in } \\
\text { tertiary resources }\end{array}$ & USA & Review of medical information resource(s) & Review \\
\hline Molassiotis et al. [32] & $\begin{array}{l}\text { Quality and safety issues of web-based } \\
\text { information about herbal medicines in the } \\
\text { treatment of cancer }\end{array}$ & China, UK & Review of medical information resource(s) & Review \\
\hline Motl et al. [11] & $\begin{array}{l}\text { Health information web sites by therapeutic } \\
\text { category for healthcare professionals }\end{array}$ & USA & Review of medical information resource(s) & Review \\
\hline Sun et al. [34] & $\begin{array}{l}\text { Development of quantitative structure-activ- } \\
\text { ity relationship models to predict potential } \\
\text { nephrotoxic ingredients in traditional } \\
\text { chinese medicines }\end{array}$ & China & Development and testing of model & Original Research \\
\hline Spanakis et al. [33] & $\begin{array}{l}\text { PharmActa: Empowering patients to avoid } \\
\text { clinical significant drug-herb interactions }\end{array}$ & Greece & Evaluation of mobile app & Original Research \\
\hline Sweet et al. [14] & $\begin{array}{l}\text { Usefulness of herbal and dietary supplement } \\
\text { references }\end{array}$ & USA & Review of medical information resource(s) & Review \\
\hline Tomasulo [35] & $\begin{array}{l}\text { Natural Standard-new integrative medicine } \\
\text { database }\end{array}$ & USA & Review of medical information resource(s) & Review \\
\hline Walker et al. [36] & $\begin{array}{l}\text { Evaluation of the ability of seven herbal } \\
\text { resources to answer questions about } \\
\text { herbal products asked in drug information } \\
\text { centers }\end{array}$ & USA & Evaluation of databases & Original Research \\
\hline Yap et al. [37] & $\begin{array}{l}\text { Utilizing mobile networks for the detection } \\
\text { of clinically relevant interactions between } \\
\text { chemotherapy regimens and complemen- } \\
\text { tary and alternative medicines }\end{array}$ & Singapore & Development of an iPhone app & Original Research \\
\hline
\end{tabular}




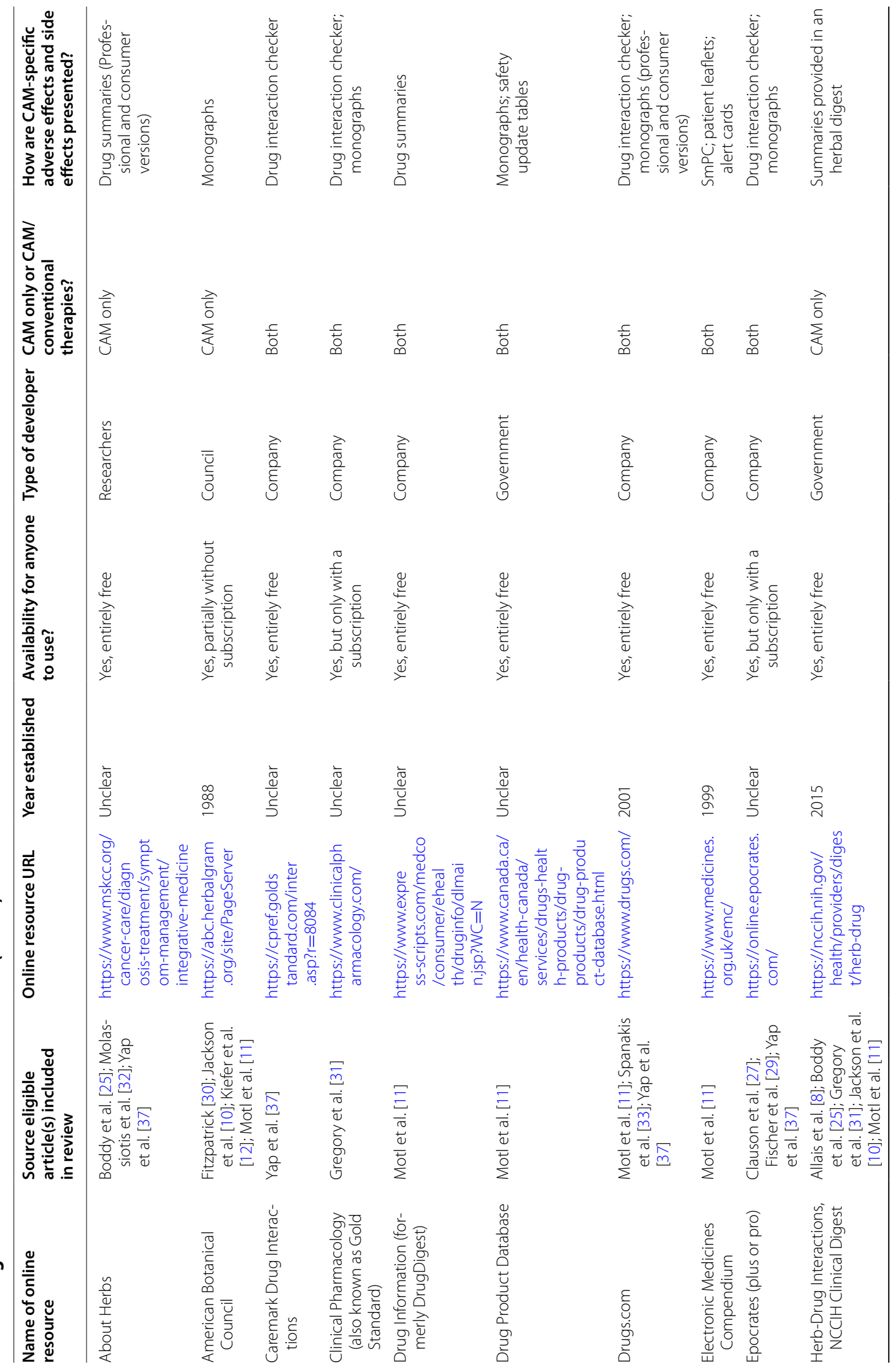




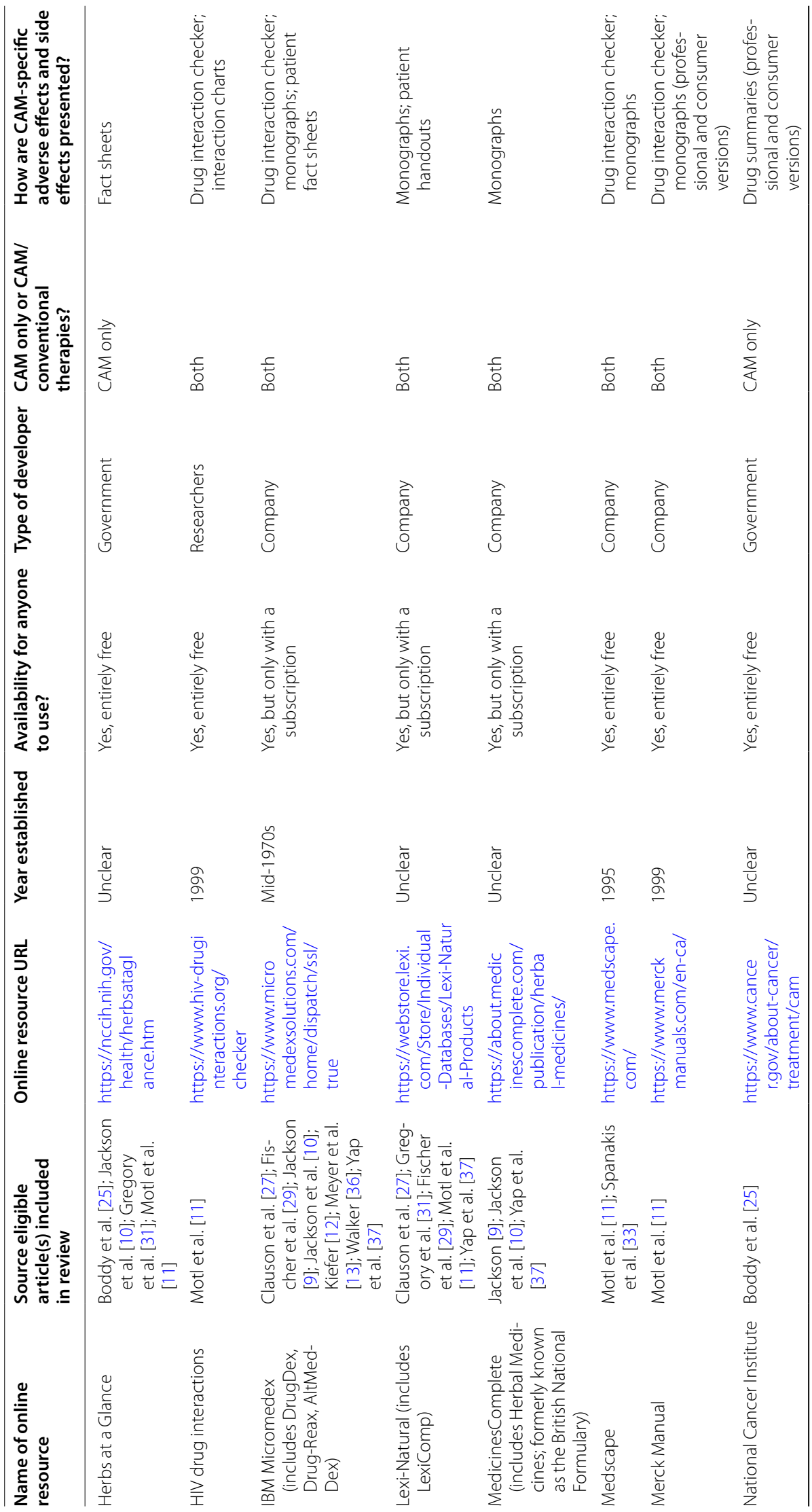




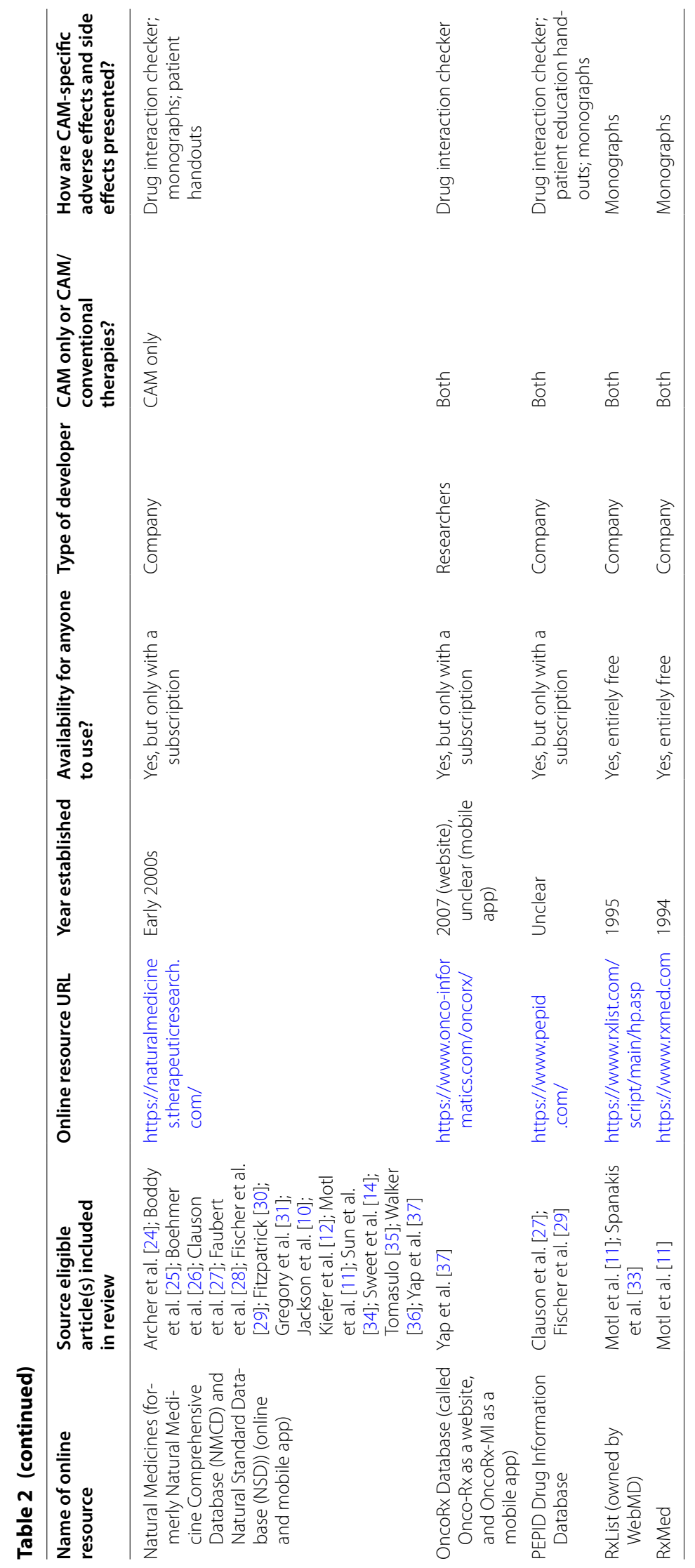


$\mathrm{Ng}$ et al. BMC Med Inform Decis Mak

(2020) 20:290

Page 16 of 20

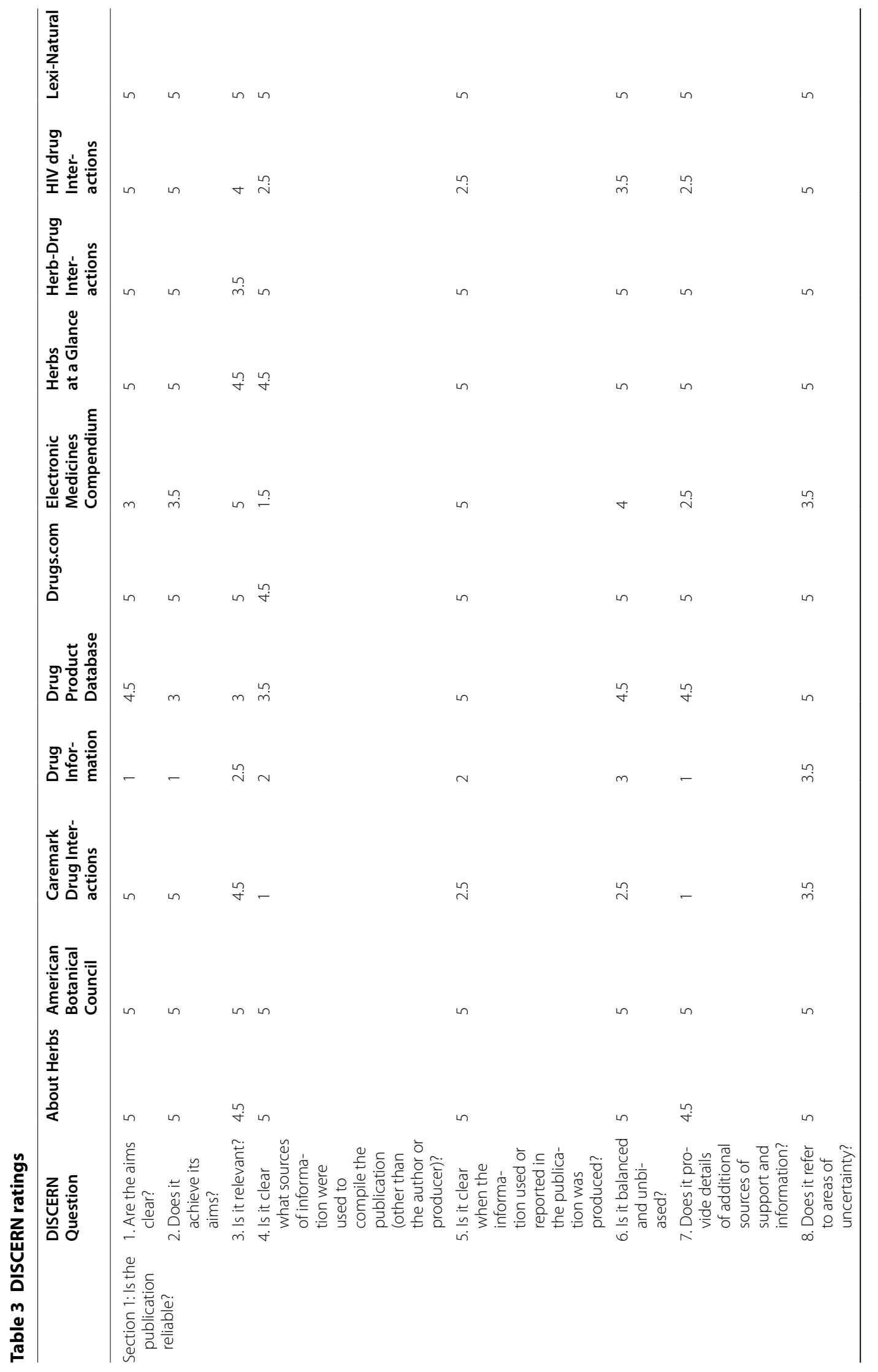




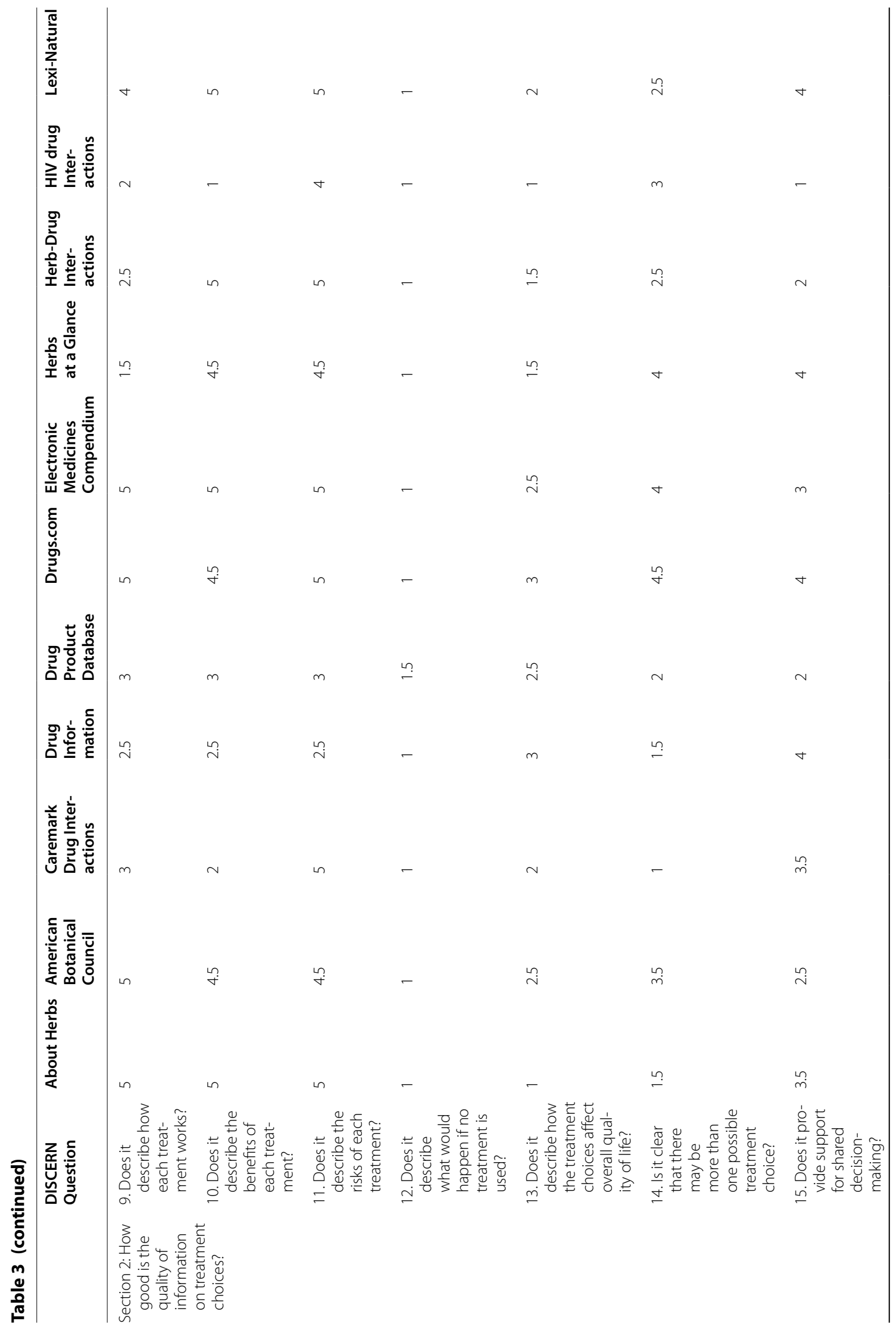




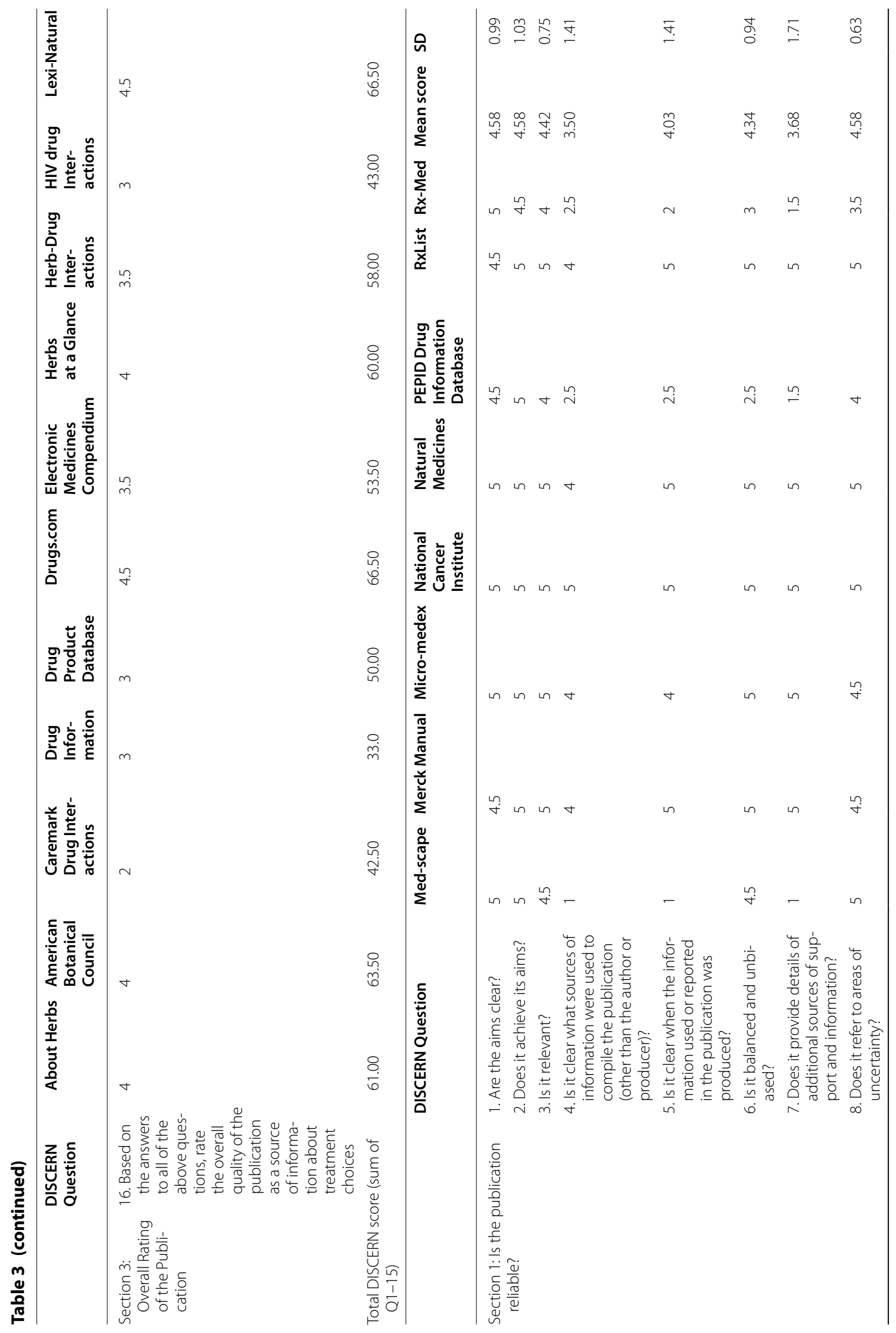




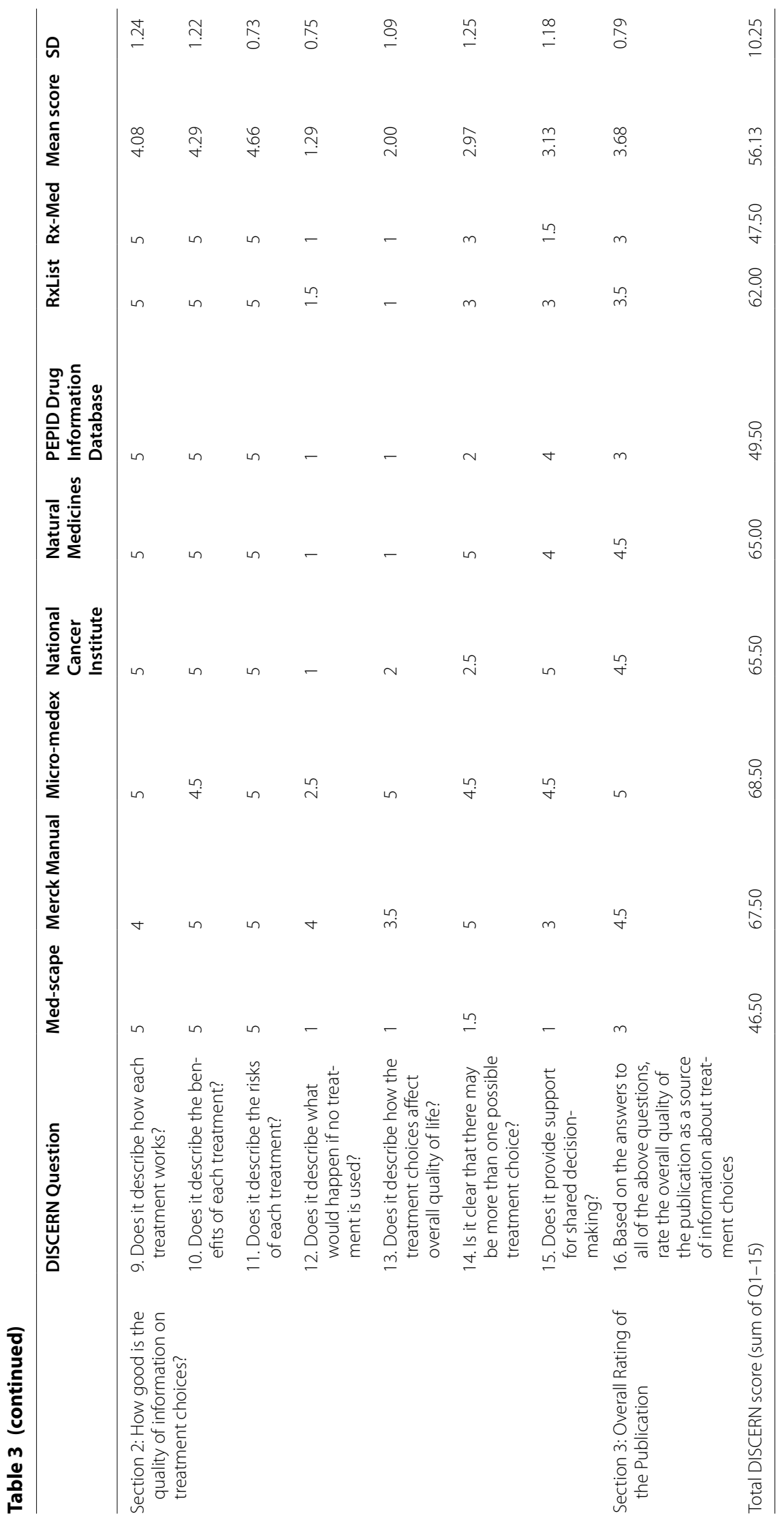


Received: 8 July 2020 Accepted: 21 October 2020

Published online: 09 November 2020

\section{References}

1. Boehm K, Raak C, Vollmar HC, Ostermann T. An overview of 45 published database resources for complementary and alternative medicine. Health Inf Libr J. 2010;27(2):93-105.

2. Ng JY, Boon HS, Thompson AK, Whitehead CR. Making sense of "alternative", "complementary", "unconventional" and "integrative" medicine: exploring the terms and meanings through a textual analysis. BMC Complement Altern Med. 2016;16:134.

3. Posadzki P, Watson LK, Ernst E. Adverse effects of herbal medicines: an overview of systematic reviews. Clin Med. 2013;13(1):7-12.4.

4. Schmitz SM, Lopez HL, Mackay D, Nguyen H, Miller PE. Serious adverse events reported with dietary supplement use in the United States: a 2.5 year experience. J Diet Suppl. 2020;17(2):227-48.

5. Ekor $M$. The growing use of herbal medicines: issues relating to adverse reactions and challenges in monitoring safety. Front Pharmacol. 2014:4:177

6. Robinson MM, Zhang X. Traditional medicines: global situation, issues and challenges. In: Proceedings of the world medicines situation 2011; Geneva: World Health Organization; 2011. p. 1-14. https://digicollection. org/hss/documents/s18063en/s18063en.pdf.

7. Canada H. Government of Canada [Internet]. About natural health products. Government of Canada; modified 2016 Mar [cited 2020 May 24]. https://www.canada.ca/en/health-canada/services/drugs-health-produ cts/natural-non-prescription/regulation/about-products.html.

8. Allais G, Voghera D, Lorenzo CD, Mana O, Benedetto C. Access to databases in complementary medicine. J Altern Complement Med. 2000;6(3):265-74

9. Jackson EA. Resources for information on herbal medicinals and dietary supplements. J Herb Pharmacother. 2001;1(2):89-98.

10. Jackson EA, KanmazT. An overview of information resources for herbal medicinals and dietary supplements. J Herb Pharmacother 2001;1(1):35-61.

11. Motl SE, Timpe EM, Robinson M, Corsberg C, Phillips K. Health information web sites by therapeutic category for healthcare professionals. J Pharm Technol . 2004:20(2):106-18.

12. Kiefer D, Shah S, Gardiner P, Wechkin H. Finding information on herbal therapy: a guide to useful sources for clinicians. Altern Ther Health Med. 2001;7(6):74-8

13. Meyer JR, Generali JA, Karpinski JL. Evaluation of herbal-drug interaction data in tertiary resources. Hosp Pharm. 2004;39(2):149-60.

14. Sweet BV, Gay WE, Leady MA, Stumpf JL. Usefulness of herbal and dietary supplement references. Ann Pharmacother. 2003;37(4):494-9.

15. Wootton JC. Directory of databases for research into alternative and complementary medicine. J Altern Complement Med. 1997;3(2):179-90.

16. Google.com. "complementary and alternative medicine". https://www. google.com/search?q=complementary+and+alternative+medicine. Accessed 8 Jun 2020.

17. Charnock D, Shepperd S, Needham G, Gann R. DISCERN: an instrument for judging the quality of written consumer health information on treatment choices. J Epidemiol Community Health. 1999;53(2):105-11.

18. World Health Organization (WHO). WHO global report on traditional and complementary medicine 2019. World Health Organization; 2019 [cited 2019 Dec 14]. Retrieved from https://www.who.int/traditional-compl ementary-integrative-medicine/WhoGlobalReportOnTraditionalAn dComplementaryMedicine2019.pdf?ua=1.

19. Aveni E, Bauer B, Ramelet AS, Decosterd I, Ballabeni P, Bonvin E, Rodondi PY. Healthcare professionals' sources of knowledge of complementary medicine in an academic center. PLoS ONE. 2017;12(9):e0184979.

20. Patel SJ, Kemper KJ, Kitzmiller JP. Physician perspectives on education, training, and implementation of complementary and alternative medicine. Adv Med Educ Pract. 2017:8:499-503.

21. Moral-Munoz JA, Carballo-Costa L, Herrera-Viedma E, Cobo MJ. Production trends, collaboration, and main topics of the integrative and complementary oncology research area: a bibliometric analysis. Integr Cancer Ther. 2019:18:1-14.
22. Ng JY, Mooghali M, Munford V. eHealth technologies assisting in identifying potential adverse interactions with complementary and alternative medicine (CAM) or standalone CAM adverse events or side effects: a scoping review. BMC Complement Med Ther. 2020;20:239.

23. Merck Manual Professional Version. Types of Complementary and Alternative Medicine. 2018. Retrieved from https://www.merckmanuals.com/ professional/special-subjects/integrative-complementary-and-alternativ e-medicine/types-of-complementary-and-alternative-medicine.

24. Archer M, Proulx J, Shane-McWhorter L, Bray BE, Zeng-Treitler Q. Development of an alert system to detect drug interactions with herbal supplements using medical record data. AMIA Annu Symp Proc. 2014:2014:249-55

25. Boddy K, Ernst E. Review of reliable information sources related to integrative oncology. Hematol Oncol Clin N Am. 2008;22(4):619-30.

26. Boehmer S, Karpa K. Evaluating the value of a web-based natural medicine clinical decision tool at an academic medical center. BMC Health Serv Res. 2011;11(1):279.

27. Clauson KA, Polen HH, Peak AS, Marsh WA, DiScala SL. Clinical decision support tools: personal digital assistant versus online dietary supplement databases. Ann Pharmacother. 2008:42(11):1592-9.

28. Faubert $\mathrm{G}$, Lebe $\mathrm{D}$, Bussières JF. A pilot study to compare natural health product-drug interactions in two databases in Canada. Pharm World Sci. 2010;32(2):179-86

29. Fischer JE, Crowell K, Curtis P. Complementary and alternative medical reference software for personal digital assistants: evidence of clinical applicability. Complement Health Pract Rev. 2005;10(1):57-72.

30. Fitzpatrick RB. Natural standard database. Med Ref Serv Quart. 2010;29(2):154-65.

31. Gregory PJ, Jalloh MA, Abe AM, Hu J, Hein DJ. Characterization of complementary and alternative medicine-related consultations in an academic drug information service. J Pharm Pract. 2016;29(6):539-42.

32. Molassiotis A, Xu M. Quality and safety issues of web-based information about herbal medicines in the treatment of cancer. Complement Ther Med. 2004;12(4):217-27.

33. Spanakis M, Sfakianakis S, Sakkalis V, Spanakis E. PharmActa: empowering patients to avoid clinical significant drug-herb interactions. Medicines. 2019;6(1):26.

34. Sun Y, Shi S, LiY, Wang Q. Development of quantitative structure-activity relationship models to predict potential nephrotoxic ingredients in traditional Chinese medicines. Food Chem Toxicol. 2019;128:163-70.

35. Tomasulo P. Natural Standard-New integrative medicine database. Med Ref Serv Quart. 2003:22(3):33-8.

36. Walker JB. Evaluation of the ability of seven herbal resources to answer questions about herbal products asked in drug information centers. Pharmacotherapy. 2002;22(12):1611-5.

37. Yap KY, See CS, Kuo EY, Chui WK, Chan A. Utilizing mobile networks for the detection of clinically relevant interactions between chemotherapy regimens and complementary and alternative medicines. J Altern Complement Med. 2012;18(2):165-74

38. Sbaffi L, Rowley J. Trust and credibility in web-based health information: a review and agenda for future research. J Med Internet Res. 2017;19(6):e218.

39. Vega LC, Montague E, DeHart T. Trust between patients and health websites: a review of the literature and derived outcomes from empirical studies. Health Technol. 2011;1(2-4):71-80.

40. National Center for Complementary and Integrative Health. Natural Doesn't Necessarily Mean Safer, or Better [Internet]. U.S. Department of Health and Human Services; updated 2020 May [cited 2020 May 24]. https://www.nccih.nih.gov/health/know-science/natural-doesnt-meanbetter.

41. Berland GK, Elliott MN, Morales LS, Algazy Jl, Kravitz RL, Broder MS, et al. Health information on the Internet: Accessibility, quality, and readability in english and spanish. JAMA. 2001;285(20):2612-21.

42. Crocco AG, Villasis-Keever M, Jadad AR. Analysis of cases of harm associated with use of health information on the internet. JAMA. 2002:287(21):2869-71.

\section{Publisher's Note}

Springer Nature remains neutral with regard to jurisdictional claims in published maps and institutional affiliations. 